\title{
Association of Adherence to a Mediterranean Diet with Excess Body Mass, Muscle Strength and Physical Performance in Overweight or Obese Adults with or without Type 2 Diabetes: Two Cross-Sectional Studies
}

\author{
Amy Buchanan and Anthony Villani *(D) \\ School of Health and Behavioural Sciences, University of the Sunshine Coast, \\ Sunshine Coast, QLD 4556, Australia; agb012@student.usc.edu.au \\ * Correspondence: avillani@usc.edu.au; Tel.: +61-7-5456-3546
}

check for updates

Citation: Buchanan, A.; Villani, A.

Association of Adherence to a

Mediterranean Diet with Excess Body Mass, Muscle Strength and Physical Performance in Overweight or Obese Adults with or without Type 2 Diabetes: Two Cross-Sectional Studies. Healthcare 2021, 9, 1255. https://doi.org/10.3390/ healthcare9101255

Academic Editors: Chrysi Koliaki, Alessandro Sartorio and Rahman Shiri

Received: 24 August 2021 Accepted: 21 September 2021 Published: 24 September 2021

Publisher's Note: MDPI stays neutral with regard to jurisdictional claims in published maps and institutional affiliations.

Copyright: (c) 2021 by the authors. Licensee MDPI, Basel, Switzerland. This article is an open access article distributed under the terms and conditions of the Creative Commons Attribution (CC BY) license (https:// creativecommons.org/licenses/by/ $4.0 /)$.

\begin{abstract}
Overweight and obesity in older adults is associated with disability and is exacerbated by the presence of type 2 diabetes (T2DM). There is emerging evidence that adherence to a Mediterranean diet (MedDiet) reduces adiposity and attenuates physical disability. These cross-sectional studies explored the associations of adherence to a MedDiet with body mass index (BMI), adiposity, muscle strength, and physical performance in older adults without diabetes and in middle-aged or older adults with T2DM. MedDiet adherence was assessed using the Mediterranean Diet Adherence Screener. Fat mass and percent body fat were assessed by dual energy X-ray absorptiometry. Muscle strength was assessed using hand-grip strength, while physical performance was assessed using the Short Physical Performance Battery and gait speed. A total of $n=87$ participants with T2DM (T2DM sample: $71.2 \pm 8.2$ years, BMI: $29.5 \pm 5.9$ ) and $n=65$ participants without diabetes (non-T2DM sample: $68.7 \pm 5.6$ years, BMI: $33.7 \pm 4.9$ ) were included in these analyses. In the T2DM sample, when controlled for age, gender, and appendicular lean mass index, adherence to a MedDiet was inversely associated with BMI, fat mass, and percent body fat. However, this was no longer maintained in the fully adjusted models. Although, adherence to a MedDiet was positively associated with gait speed ( $\beta=0.155 ; p=0.050)$ independent of all covariates used. Adherence to a MedDiet may be a suitable dietary strategy for preserving lower body physical function in middle-aged and older adults with T2DM. However, these findings should be further investigated using well-designed randomised controlled trials and prospective cohort studies with a wider range of adherence scores to investigate temporal associations.
\end{abstract}

Keywords: Mediterranean diet; adiposity; muscle strength; physical performance; type 2 diabetes mellitus; ageing

\section{Introduction}

With improved life expectancy in an ageing population, the preservation of musculoskeletal health in later life has become increasingly important [1]. Physiological ageing is associated with the gradual loss of lean body mass and the simultaneous increase in adipose tissue and ectopic fat. Consequent reductions in muscle strength and physical performance heighten the vulnerability of middle-aged and older adults to mobility disability, hospitalisations, and loss of independence [2,3], especially in the presence of multiple comorbidities [4] and increasing rates of obesity [5]. Age-related changes in body composition are also unfavourable from a metabolic perspective, with evidence suggesting that additional body fat and reduced muscle mass may contribute to the development of cardiometabolic diseases, including type 2 diabetes mellitus (T2DM) [6-9]. This is potentially a bidirectional relationship, as the loss of lean body mass, strength, and function is proposed to be accelerated in T2DM [10-12] due to underlying pathological mechanisms of 
insulin resistance, hyperglycaemia, inflammation, and oxidative stress [13]. Consequently, middle-aged and older adults with T2DM are likely to be at a higher risk of adverse musculoskeletal outcomes than those without T2DM, threatening the ability to carry out normal daily activities and negatively affecting quality of life [14,15]. Given that secular trends in diabetes incidence are forecasted to increase in the coming decades [16], strategies to attenuate adiposity and musculoskeletal decline in middle-aged and older adults with T2DM is warranted.

The treatment of T2DM includes a strong focus on weight management by targeting modifiable risk factors including physical activity and nutrition [17]. Of note, resistance training has been associated with improvements in fat mass, lean body mass, and muscle strength in adults with T2DM [18]. In contrast, effective dietary strategies to support musculoskeletal health in older patients with T2DM is less clear. An energy-restricted diet in older adults is currently debated, as resulting energy-restricted weight loss consists of both fat mass and lean body mass [19]. Furthermore, weight regain in older adults is likely to primarily comprise of fat mass [20,21]. This may exacerbate functional and metabolic consequences already present as a result of ageing and T2DM. However, there is evidence to suggest that energy-restricted diets that are higher in protein [22] or combined with physical activity $[23,24]$ may attenuate declines in lean body mass. Evidence for the efficacy of other single-nutrient dietary strategies, including carbohydrate restriction [25], on weight loss in T2DM patients remains equivocal.

There has been growing interest into dietary patterns as a determinant of chronic disease risk over the life course [26], with the Mediterranean diet (MedDiet) one of the most highly investigated for the management of T2DM [27,28]. The traditional MedDiet is a dietary pattern consistent with that typically consumed by populations living in the olive growing regions of the Mediterranean basin before the mid-1960s. Although often described as a 'diet' in the research literature, in reality the MedDiet is more correctly recognisable as a 'whole lifestyle' approach, which also incorporates time-honoured behaviours, including harvesting, traditional culinary techniques, frugality, and conviviality [29-31]. Nevertheless, from a dietary perspective, the MedDiet is often described as a plant-based dietary pattern, consistent with a high intake of vegetables, fruits, nuts, legumes, unprocessed cereals, and daily use of extra-virgin olive oil incorporated into all meals; moderate consumption of fish, shellfish, fermented dairy products (cheese and yoghurt), and wine (typically during meals); and a low or infrequent consumption of meat and meat products, processed cereals, sweets, vegetable oils, and butter $[32,33]$. As a result of its putative beneficial health effects on cardiometabolic health and healthy ageing, the MedDiet is one of the most widely evaluated dietary patterns in the scientific literature, which includes positive effects on musculoskeletal and functional outcomes in older adults [34-36]. Although there is less available evidence supporting this relationship in patients with T2DM, similar findings are beginning to emerge [37,38]. Lastly, adherence to a MedDiet is also inversely associated with adiposity, and in particular, central adiposity $[39,40]$. However, to the best of our knowledge, the relationship between adherence to a MedDiet and various indices of adiposity and physical function is yet to be thoroughly investigated in vulnerable older populations, including those with T2DM. Therefore, this study explored the independent association between adherence to a MedDiet, body mass index (BMI), and measures of adiposity, strength, and physical performance in community-dwelling, middle-aged and older adults with and without T2DM.

\section{Materials and Methods}

\subsection{Participants and Recruitment}

This study included the use of two separate cross-sectional analyses involving two groups of community-dwelling, middle-aged and older adults recruited from two distinct studies conducted by our group [41,42]. The first study was a 12-week randomised controlled trial with a sample population of otherwise healthy overweight and obese older adults aged $\geq 60$ years, with a $\mathrm{BMI} \geq 27 \mathrm{~kg} / \mathrm{m}^{2}$ [41]. Baseline data from this group will 
be used for the purposes of the present study, and will be referred to as the non-T2DM sample. The second study was a cross-sectional analysis of adults aged $\geq 50$ years with a confirmed diagnosis of T2DM [42], referred to as the T2DM sample. Exclusion criteria for both groups included the presence of cancer; respiratory, neurological, and renal diseases; physical disability; poor cognition/unable to provide informed consent; and current or recent use of anti-inflammatory drugs corticosteroid agents or sex steroid compounds. All participants were local to the Sunshine Coast, Queensland, Australia, and were recruited using social media platforms, printed flyers, and newspaper advertisements. Both studies were conducted in accordance with the guidelines described in the Declaration of Helsinki and all procedures involving human subjects were approved by the Human Research Ethics Committee (A/16/801) (S/171/123), University of the Sunshine Coast, Queensland, Australia. Written informed consent was obtained from all participants.

\subsection{Outcome Measures}

Detailed information regarding outcome measures described in the present study have been reported elsewhere [41,42]. Briefly, key outcomes included assessment of fat mass, percent body fat, hand-grip strength, and measures of physical performance including gait speed and the Short Physical Performance Battery.

\subsection{Anthropometry and Body Composition}

Body weight was measured using a calibrated digital scale (AND Weighing; HW-KGL, Melbourne, Australia) accurate to the nearest $0.1 \mathrm{~kg}$, with participants barefoot and wearing light clothing. A wall-mounted stadiometer (Holtain Limited, Crymych, United Kingdom) was used to measure height to the nearest $0.1 \mathrm{~cm}$. BMI was calculated using weight $(\mathrm{kg})$ divided by height squared $\left(\mathrm{m}^{2}\right)$. Dual-energy X-ray absorptiometry (DXA) (Lunar iDXA: GE Healthcare, Madison, WI, USA) with GE encore densitometry software (version 16; GE Healthcare) was used to assess whole body composition for estimates of fat mass, total percent body fat, and appendicular lean mass. The sum of lean soft tissue mass in both arms and legs was used to determine total appendicular lean mass. The appendicular lean mass index was calculated using the formula, appendicular lean mass $/ \mathrm{height} \mathrm{t}^{2}\left(\mathrm{~kg} / \mathrm{m}^{2}\right)$ [43]. A single trained technician performed and interpreted all DXA scans in accordance with the Nana et al. protocol [44].

\subsection{Isometric Hand-Grip Strength}

A calibrated hand-held dynamometer (Smedley, Tokyo, Japan) was used to assess isometric hand-grip strength of the dominant hand to the nearest $0.5 \mathrm{~kg}$. Participants were instructed to exert maximal force on the dynamometer while moving the dominant hand from a raised position above the head downwards in a 180-degree arc. One practice trial was permitted followed by three recorded measurements, each separated by a 60 -s recovery period. The mean of the three measures was used for analysis.

\subsection{Measures of Physical Performance}

Physical performance was investigated using the Short Physical Performance Battery, a composite measure of three physical tests that stimulate domains of lower extremity function required for activities of daily living, including: (1) balance, (2) lower limb strength, and (3) gait speed [45]. For balance, participants were assessed on their ability to stand in three hierarchal positions with their feet together, semi-tandem, or full-tandem. Lower limb strength was assessed by the completion of five consecutive chair stands without the use of upper extremities. The assessment of gait speed involved participants walking at their usual walking speed without acceleration over a measured distance of 4 metres. Each physical test received a rank from 0-4 and were summed, with higher performance represented by a higher total score. Gait speed was also used as an independent measure of physical performance, with two additional trials timed using a stopwatch. The mean of the two measures was used for analysis. 


\subsection{Adherence to a MedDiet}

MedDiet adherence was assessed using the Mediterranean Diet Adherence Screener, a previously validated 14-item tool developed and used in the Prevención con Dieta Mediterránea (PREDIMED) study [46]. Dietary adherence scores are based on pre-defined criteria for consumption and frequency of 12 main dietary components and two food habits related to a Mediterranean dietary pattern. Each item in the tool was dichotomously scored as either 0 or 1, producing a maximum score of 14 . Greater adherence to a MedDiet is indicated by a higher score, with categorisation reflecting low (score $\leq 5$ ), moderate (score 6-9), or high (score $\geq 10$ ) adherence. For the purpose of the present study, MedDiet adherence was reported as a continuous variable in each of the regression models.

\subsection{Statistical Analysis}

All continuous variables are expressed as means \pm standard deviations (SD). The Kolmogorov-Smirnov statistic was used to assess normality of data prior to all tests, and multiple regression diagnostics were performed to ensure assumptions of multicollinearity and homoscedasticity were not violated. Independent samples $t$ tests were used to identify differences in baseline characteristics between the two study groups. Pearson's correlation coefficients were used independently per study group to identify associations between adherence to a MedDiet and BMI, measures of adiposity, hand-grip strength, and physical performance. Univariable and multivariable linear regression analysis (and 95\% CI) was also used to investigate the independent association between adherence to a MedDiet and BMI, measures of adiposity, hand-grip strength, and physical performance using one unadjusted and four adjusted predictor models. Standardised beta-coefficients were used in the univariable and multivariable linear regressions with z-scores for all outcome variables calculated before running each of the regression models. Therefore, the beta-coefficients are interpreted as the change in the predicted value for each of the outcomes based on a standard deviation increase in the Mediterranean Diet Adherence Screener score. Analyses were performed using Statistical Package for the Social Sciences (SPSS) for Windows 26.0 software (IBM Corp., Armonk, NY, USA), with statistical significance set at $p \leq 0.05$.

\section{Results}

A total of $n=87$ (male, $n=58$; female, $n=29$ ) middle-aged and older overweight or obese community-dwelling adults with T2DM were included as part of the T2DM study sample. A further $n=65$ (male, $n=22$; female, $n=43$ ) older overweight or obese community-dwelling adults were included as part of the non-T2DM sample. Participant characteristics according to the two study samples are shown in Table 1. As expected, the non-T2DM sample had a significantly greater body weight $(p=0.002)$, BMI $(p<0.001)$, fat mass $(p<0.001)$, and percent body fat $(p<0.001)$. This sample of participants also had a significantly greater appendicular lean mass index $(p=0.050)$ and faster gait speed $(p<0.001)$. Adherence to a MedDiet was not significantly different between the two study groups.

In the T2DM sample, Pearson's correlation coefficients showed a small to moderate positive association between adherence to a MedDiet and lower body extremity function including gait speed $(r=0.362, p<0.001)$ and the Short Physical Performance Battery score $(r=0.243, p=0.023)$. Furthermore, independent analysis of the non-T2DM sample found an inverse association between MedDiet adherence and BMI $(r=-0.274, p=0.027)$. 
Table 1. Participant characteristics according to the two separate (T2DM sample vs. non-T2DM sample) study groups of middle-aged and older adults.

\begin{tabular}{|c|c|c|c|}
\hline Characteristics & $\begin{array}{l}\text { T2DM Sample } \\
\quad(n=87)\end{array}$ & $\begin{array}{l}\text { Non-T2DM Sample } \\
\quad(n=65)\end{array}$ & $p$ \\
\hline Age (years) & $71.2 \pm 8.2$ & $68.7 \pm 5.6$ & 0.040 \\
\hline Weight (kg) & $85.1 \pm 19.5$ & $94.3 \pm 14.9$ & 0.002 \\
\hline $\operatorname{BMI}\left(\mathrm{kg} / \mathrm{m}^{2}\right)$ & $29.5 \pm 5.9$ & $33.7 \pm 4.9$ & $<0.001$ \\
\hline Fat mass (kg) & $31.3 \pm 11.1$ & $40.3 \pm 9.5$ & $<0.001$ \\
\hline Percent body fat (\%) & $37.9 \pm 7.3$ & $44.6 \pm 7.3$ & $<0.001$ \\
\hline Appendicular lean mass index $\left(\mathrm{kg} / \mathrm{m}^{2}\right)$ & $7.7 \pm 1.5$ & $8.2 \pm 1.2$ & 0.050 \\
\hline Hand-grip strength $(\mathrm{kg})$ & $33.4 \pm 10.8$ & $30.8 \pm 10.6$ & 0.138 \\
\hline Gait speed $(\mathrm{m} / \mathrm{s})$ & $0.9 \pm 0.2$ & $1.1 \pm 0.2$ & $<0.001$ \\
\hline $\begin{array}{l}\text { Short Physical Performance Battery } \\
\text { score (0-12 points) }\end{array}$ & $10.7 \pm 2.1$ & $10.6 \pm 1.6$ & 0.742 \\
\hline $\begin{array}{l}\text { Mediterranean Diet Adherence } \\
\text { Screener score (0-14 points) }\end{array}$ & $5.6 \pm 2.3$ & $4.9 \pm 2.0$ & 0.070 \\
\hline
\end{tabular}

Data expressed as mean \pm SD. T2DM, type 2 diabetes mellitus; BMI, body mass index. $p$-value refers to significant differences between T2DM and non-T2DM study groups.

Table 2 presents standardised beta-coefficients (and 95\% CI) from univariable and multivariable linear regression analysis reported for independent associations between MedDiet adherence and BMI, measures of adiposity, hand-grip strength, and physical performance. When analysing both groups independently, in the T2DM sample, adherence to a MedDiet was inversely associated with BMI (Beta $=-0.200 ; 95 \%$ CI: $-0.329-0.061$; $p=0.005)$, fat mass (Beta $=-0.230 ; 95 \%$ CI: $-0.385-0.050 ; p=0.012$ ) and percent body fat (Beta $=-0.187 ; 95 \%$ CI: $-0.330-0.001 ; p=0.048$ ) independent of age, gender, and appendicular lean mass index. However, this inverse relationship was not maintained in the fully adjusted model. Nevertheless, a significant positive association was observed between MedDiet adherence and gait speed (Beta $=0.155 ; 95 \%$ CI: 0.006-0.283; $p=0.050$ ) independent of all covariates used in the present study. In the non-T2DM sample, adherence to a MedDiet was not associated with adiposity. A significant positive association was observed between MedDiet adherence and gait speed (Beta $=0.265 ; 95 \%$ CI: $0.017-0.519 ; p=0.037$ ). However, this relationship was not maintained in the fully adjusted model. 


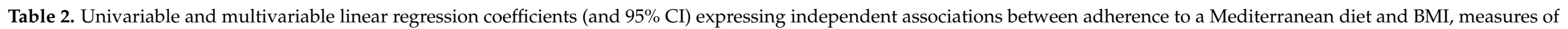
adiposity, hand-grip strength, and physical performance by population sample. (standardised beta-coefficient (Beta)) ${ }^{a}$.

\begin{tabular}{|c|c|c|c|c|c|c|c|c|c|c|c|c|c|}
\hline \multirow[t]{2}{*}{ Population Sample } & \multirow[t]{2}{*}{ Model } & \multicolumn{2}{|l|}{ BMI } & \multicolumn{2}{|l|}{ Fat Mass } & \multicolumn{2}{|l|}{ Percent Body Fat } & \multicolumn{2}{|c|}{ Hand-Grip Strength } & \multicolumn{2}{|l|}{ Gait Speed } & \multicolumn{2}{|c|}{$\begin{array}{l}\text { Short Physical Performance } \\
\text { Battery }\end{array}$} \\
\hline & & Beta & $p$ & Beta & $p$ & Beta & $p$ & Beta & $p$ & Beta & $p$ & Beta & $p$ \\
\hline \multirow{5}{*}{$\mathrm{T} 2 \mathrm{DM}$} & $1^{\mathrm{b}}$ & $-0.129(-0.334,0.083)$ & 0.235 & $-0.173(-0.364,0.038)$ & 0.110 & $-0.136(-0.310,0.069)$ & 0.209 & $\begin{array}{c}0.022 \\
(-0.218,4.806)\end{array}$ & 0.840 & $\begin{array}{c}0.362 \\
(0.144,0.504)\end{array}$ & 0.001 & $\begin{array}{c}0.243 \\
(0.037,0.486)\end{array}$ & 0.023 \\
\hline & $2^{c}$ & $-0.208(-0.400,-0.005$ & 0.044 & $-0.236(-0.423,-0.023)$ & 0.029 & $-0.190(-0.339,0.069)$ & 0.053 & $\begin{array}{c}0.093 \\
(-0.308,3.270)\end{array}$ & 0.994 & $\begin{array}{c}0.291 \\
(0.088,0.437)\end{array}$ & 0.004 & $0.161(-0.035,0.380)$ & 0.102 \\
\hline & $3^{d}$ & $-0.200(-0.329,-0.061)$ & 0.005 & $-0.230(-0.385,-0.050)$ & 0.012 & $-0.187(-0.330,-0.001)$ & 0.048 & $\begin{array}{c}0.086 \\
(-0.339,3.412)\end{array}$ & 0.994 & $\begin{array}{c}0.291 \\
(0.083,0.438)\end{array}$ & 0.004 & $0.161(-0.036,0.381)$ & 0.104 \\
\hline & $4^{\mathrm{e}}$ & $\begin{array}{c}-0.036 \\
(-0.085,0.015)\end{array}$ & 0.171 & $\begin{array}{c}-0.009 \\
(-0.059,0.041)\end{array}$ & 0.727 & $\begin{array}{c}-0.039 \\
(-0.032,0.101)\end{array}$ & 0.309 & $\begin{array}{c}0.010 \\
(-0.367,6.662)\end{array}$ & 0.936 & $\begin{array}{c}0.212 \\
(0.006,0.374)\end{array}$ & 0.039 & $\begin{array}{c}0.088 \\
(-0.124,0.312)\end{array}$ & 0.393 \\
\hline & $5^{\mathrm{f}}$ & $-0.026(-0.07,0.026)$ & 0.331 & $-0.011(-0.062,0.040)$ & 0.674 & $-0.037(-0.032,0.102)$ & 0.352 & $\begin{array}{c}0.005 \\
(-0.312,4.119)\end{array}$ & 0.967 & $\begin{array}{c}0.155 \\
(0.006,0.283)\end{array}$ & 0.050 & $\begin{array}{c}0.040 \\
(-0.207,0.121) \\
(\end{array}$ & 0.602 \\
\hline \multirow{5}{*}{ Non-T2DM } & $1^{\mathrm{b}}$ & $-0.274(-0.464,-0.029$ & 0.027 & $-0.034(-4.155,0.920)$ & 0.790 & $-0.034(-0.097,1.190)$ & 0.788 & $\begin{array}{c}0.030 \\
(-0.233,0.297)\end{array}$ & 0.811 & $0.227(0.018,0.478)$ & 0.068 & $\begin{array}{c}-0.048(-0.263 \\
0.183)\end{array}$ & 0.707 \\
\hline & $2^{c}$ & $-0.228(-0.422,0.012)$ & 0.064 & $-0.044(-4.755,0.985)$ & 0.731 & $0.045(-2.038,2.534)$ & 0.729 & $\begin{array}{c}0.058 \\
(-0.125,0.248)\end{array}$ & 0.512 & $\begin{array}{c}0.259 \\
(0.010,0.513)\end{array}$ & 0.042 & $\begin{array}{c}-0.042(-0.271 \\
0.195)\end{array}$ & 0.746 \\
\hline & $3^{d}$ & $-0.230(-0.426,0.012)$ & 0.064 & $-0.120(-0.107,0.347)$ & 0.249 & $-0.001(-0.042,0.514)$ & 0.094 & $\begin{array}{c}0.057 \\
(-0.128,0.247)\end{array}$ & 0.528 & $\begin{array}{c}0.265 \\
(0.017-0.519)\end{array}$ & 0.037 & $\begin{array}{c}-0.027 \\
(-0.245,0.197)\end{array}$ & 0.828 \\
\hline & $4^{\mathrm{e}}$ & $\begin{array}{c}-0.230 \\
(-0.426,0.012)\end{array}$ & 0.063 & $\begin{array}{c}-0.078 \\
(-0.185,0.028)\end{array}$ & 0.145 & $\begin{array}{c}-0.039 \\
(-0.028,0.185)\end{array}$ & 0.145 & $\begin{array}{c}0.017 \\
(-0.171,0.208)\end{array}$ & 0.847 & $\begin{array}{c}0.168 \\
(-0.068,0.407)\end{array}$ & 0.158 & $\begin{array}{c}-0.061 \\
(-0.282,0.172)\end{array}$ & 0.630 \\
\hline & $5^{\mathrm{f}}$ & $-0.117(-0.31,0.108)$ & 0.329 & $-0.088(-0.188,0.012)$ & 0.084 & $-0.088(-0.012,0.188)$ & 0.084 & $\begin{array}{c}0.010 \\
(-0.172,0.192)\end{array}$ & 0.913 & $\begin{array}{c}0.182 \\
(-0.038,0.406)\end{array}$ & 0.102 & $\begin{array}{c}-0.121 \\
(-0.317,0.099)\end{array}$ & 0.299 \\
\hline
\end{tabular}

BMI, body mass index; T2DM, type 2 diabetes mellitus. ${ }^{\text {a }}$ Standardised beta coefficient represents the change in a SD-unit increase in the Mediterranean Diet Adherence Screener score per change in outcome measure. ${ }^{\mathrm{b}}$ Non-adjusted model. ${ }^{\mathrm{c}}$ Adjusted for age and gender. ${ }^{\mathrm{d}}$ Adjusted for age, gender, and appendicular lean mass index. ${ }^{\mathrm{e}} \mathrm{BMI}$ adjusted for age, gender, appendicular lean mass index, fat mass, and percent body fat; Fat mass adjusted for age, gender, appendicular lean mass index, BMI, and percent body fat; Percent body fat adjusted for age, gender, appendicular lean mass index, BMI, and fat mass; Hand-grip strength adjusted for age, gender, appendicular lean mass index, BMI, fat mass, and percent body fat; Gait speed adjusted for age, gender, appendicular lean mass index, BMI, fat mass, and percent body fat; Short Physical Performance Battery adjusted for age, gender, appendicular lean mass index, BMI, fat mass, and percent body fat. ${ }^{\mathrm{f}}$ BMI adjusted for age, gender, appendicular lean mass index, fat mass, percent body fat, hand-grip strength, gait speed, and Short Physical Performance Battery; Fat mass adjusted for age, gender, appendicular lean mass index, BMI, percent body fat, hand-grip strength, gait speed, and Short Physical Performance Battery; Percent body fat adjusted for age, gender, appendicular lean mass index, BMI, fat mass, hand-grip strength, gait speed, and Short Physical Performance Battery; Hand-grip strength adjusted for age, gender, appendicular lean mass index, BMI, fat mass, percent body fat, gait speed, and Short Physical Performance Battery; Gait speed Physical Performance Battery; Hand-grip strength adjusted for age, gender, appendicular lean mass index, BMI, fat mass, percent body fat, gait speed, and Short Physical Performance Battery; Gait speed
adjusted for age, gender, appendicular lean mass index, BMI, fat mass, percent body fat, hand-grip strength, and Short Physical Performance Battery; Short Physical Performance Battery adjusted for age, gender, appendicular lean mass index, BMI, fat mass, percent body fat, hand-grip strength, and gait speed. 


\section{Discussion}

To the best of our knowledge, this is one of the first Australian studies to investigate the relationship between MedDiet adherence, adiposity, and physical function in a vulnerable older group at risk of functional decline and mobility disability. We showed that adherence to a MedDiet was not associated with BMI and measures of adiposity in the fully adjusted models used in the present study. However, MedDiet adherence was positively associated with gait speed in the T2DM sample, strengthening the current evidence for the potential role of healthy dietary patterns in attenuating functional decline in vulnerable older adults with chronic disease.

There is previous evidence to support that adherence to healthy dietary patterns, including the MedDiet, is inversely associated with central obesity $[47,48]$. Specifically, in relation to a diabetic population, results from the present study were somewhat consistent with the overarching literature demonstrating the potential benefits of a MedDiet intervention to support weight loss in overweight and obese adults. In brief, two previously published systematic reviews of randomised controlled trials identified that a MedDiet intervention was effective in reducing BMI [49] and body weight $[49,50]$ in overweight and obese adults across all ages in patients with T2DM. Vitale et al. reported an inverse association between MedDiet adherence and BMI in $n=2568$ middle-aged and older Italians with T2DM [51]. Moreover, a post-hoc analysis of $n=191$ participants with T2DM aged 55-80 years from the PREDIMED study also reported similar findings [52]. Specifically, Lasa et al. showed that after a 1-year follow-up, participants randomised to a MedDiet intervention lost significantly more body weight and abdominal fat in comparison to the low-fat control. Although we did not report on measures of abdominal adiposity per se, we observed an inverse association between MedDiet adherence and both fat mass and percent body fat derived from DXA. Importantly, however, this inverse relationship was not maintained when controlled for BMI. Nevertheless, we present novel findings in that few studies have investigated the relationship between MedDiet adherence and measures of adiposity in a sample of middle-aged and older adults with T2DM. As such, our results provide preliminary evidence highlighting the potential benefits of a MedDiet as a dietary strategy to facilitate and promote reductions in adiposity in older adults with diabetes. Furthermore, there is previous evidence to support that adherence to a MedDiet has a myoprotective effect [53], which may attenuate the loss of lean body mass during weight management [54], making it a suitable alternative for older adults vulnerable to adverse changes in body composition and functional decline secondary to energy-restricted weight loss diets.

Several mechanisms may explain the inverse relationship between adherence to a MedDiet and adiposity. A MedDiet is predominantly plant-based and is rich in vitamins, minerals, unsaturated fatty acids, and non-nutritive functional components including polyphenols, phytosterols, and carotenoids [55]. Through the consumption of fruits, vegetables, legumes, wholegrains, nuts, and seeds, a MedDiet is also high in dietary fibre [55,56]. As such, dietary patterns high in fibre have been associated with increased satiation and satiety due to mechanisms of prolonged mastication and the reduction of speed-eating, gastric distention, and the release of cholecystokinin [56]. Furthermore, plant-based foods also have a lower energy-density, thus reducing the risk of excess energy intake and subsequent weight gain [57]. Favourable to the management of T2DM, many of these foods also have a low glycaemic load that dampens the postprandial rise in blood glucose as well as delaying the return of hunger [57,58]. Lastly, while extra virgin olive oil is a fundamental pillar of a traditional MedDiet, research has indicated that the quality of fat is more important than the quantity for the purposes of weight management. Indeed, consumption of unsaturated fats have been associated with increased beta-oxidation, diet-induced thermogenesis, and improved overall energy expenditure [59,60].

Our results further contribute to the growing body of evidence supporting a positive association between adherence to a MedDiet and physical performance in older adults. In agreement with our findings, Shahar et al. reported that greater MedDiet adherence 
was associated with a faster usual gait speed in older adults from the Health, Aging, and Body Composition (Health ABC) Cohort, with results remaining significant over an 8-year follow-up period [61]. Similar longitudinal results have also been reported in Spanish [62] and Italian [63] cohorts of older adults. However, evidence demonstrating a relationship between MedDiet adherence and hand-grip strength remains inconsistent. In the present study, we showed that adherence to a MedDiet was not associated with hand-grip strength. In contrast, positive relationships have previously been reported in Italian [64], Korean [65], and Portuguese [66] older cohorts. In agreement with findings from the present study, results from the InCHIANTI [63], TRELONG [67], and OSPTRE-FPS [68] studies all showed no relationship between MedDiet adherence and hand-grip strength. Importantly, however, the discrepancy in these findings may indeed be related to the many variations in scoring systems and indices used to quantify adherence to a MedDiet, making comparisons between studies challenging. Specifically, adherence tools such as the Mediterranean Diet Adherence Screener (used in the present study) are based on normative criterion scores, dietary characteristics, and serve sizes that are reflective of a Mediterranean-style diet; in contrast, diet quality indices such as the Mediterranean Diet Score or Alternative Mediterranean Diet Score are dependent on the habitual dietary characteristics of the study population and may not reflect true adherence to a MedDiet pattern $[69,70]$. Irrespective, few studies have investigated the relationship between MedDiet adherence and functional performance in older adults with T2DM. Tepper et al. [37] previously reported that higher adherence to a MedDiet amongst older Israeli adults with diabetes was associated with lower risk of falls and greater hand-grip strength. However, larger studies that include at-risk populations, including those with T2DM, are needed to confirm these associations and establish temporal relationships. Nevertheless, our results support the potential role of a Mediterranean-style diet to support functional status (e.g., lower body extremity function) as a key component of healthy ageing. Mechanistically, the potential benefits of adherence to a MedDiet and functional status in older adults with chronic disease are likely attributable to the synergistic relationship of nutrients and their role in attenuating processes including inflammation and oxidative stress [53,71]. Low-grade chronic inflammation has been reported in many age-related conditions, including the deterioration of skeletal muscle [72]. Specifically, cytokines including C-reactive protein, interleukin-6, and tumour necrosis factor- $\alpha$ have previously been implicated in the loss of muscle mass, strength, and physical performance in older adults [73-75]. A proinflammatory state has also been associated with visceral adiposity and metabolic diseases such as T2DM [72,76], increasing the vulnerability of affected older adults to musculoskeletal and functional decline. However, the high antioxidant capacity of a MedDiet has a key role in modulating signalling pathways involved in the production of inflammatory mediators and reactive oxygen species [77], thereby dampening the inflammatory response, which may aid in preserving muscle integrity. Nevertheless, adherence to a MedDiet and improved functional status may be a marker of healthier lifestyle behaviours and quality of life. Specifically, reverse causation is plausible whereby participants with higher adherence to a MedDiet may also be more physically active and have a better health-related quality of life and, therefore, have greater physical capabilities.

There are several limitations that must be considered in the interpretation of our findings. Firstly, our results may indeed be overstated given that the sample size was relatively small and not generalizable to a wider population of older adults with and without chronic disease. Specifically, an important consideration in the interpretation of our findings is the potential for selection bias at study entry and the heterogeneity in known clinical characteristics between the two study groups. For example, the T2DM sample was significantly older and displayed a slower gait speed. In contrast, the non-T2DM sample had a significantly greater body weight, BMI, and measures of adiposity. Furthermore, despite adjusting for important covariates in our multivariable linear regression, residual confounding cannot be eliminated. For example, we did not control for glycaemia (e.g., $\mathrm{HbA1c}$, glucose, insulin resistance, etc.), blood lipids, and inflammatory markers upon 
study recruitment, all of which may impact musculoskeletal health and function [78-80]. Additional, yet important, confounders requiring consideration include habitual physical activity status, dietary intake (energy and protein in particular), and medication use. Specifically, structured physical activity interventions (particularly resistance exercise) improve body composition (i.e., increase fat-free mass and reduce adiposity), muscle strength, physical performance, and glycaemic control in overweight and obese older adults with and without T2DM $[81,82]$. In the present study, we also did not consider the use and/or impact of oral hypoglycaemic agents, such as metformin, on changes in body composition, which have been shown in clinical trials to facilitate weight loss [83]. Moreover, adherence scores in the present study were also low to moderate. As of consequence, this limits the generalizability of our results given the low frequency of high adherence scores. Lastly, the cross-sectional design of the present study prevents causality from being determined.

\section{Conclusions}

These cross-sectional analyses showed that adherence to a MedDiet was positively associated with gait speed in middle-aged and older adults with T2DM. Although we are unable to rule out residual confounding, our results do provide novel evidence to suggest that a MedDiet pattern may be a suitable dietary strategy to promote healthy musculoskeletal function in overweight and obese adults with diabetes. However, these findings should be further investigated using well-designed and robust randomised controlled trials and prospective cohort studies with a wide range of adherence scores in order to investigate temporal associations while controlling for important confounders to ascertain the strength of this relationship.

Author Contributions: Conceptualization, A.V.; methodology, A.V.; software, A.B. and A.V.; validation, A.V.; formal analysis, A.B. and A.V.; investigation, A.V.; resources, A.V.; data curation, A.V.; writing—original draft preparation, A.B.; writing — review and editing, A.B. and A.V.; visualization, A.V.; supervision, A.V.; project administration, A.V.; funding acquisition, A.V. All authors have read and agreed to the published version of the manuscript.

Funding: A.V. was supported with start-up funds from the School of Health and Behavioural Sciences at the University of the Sunshine Coast. No external funding was awarded for this project.

Institutional Review Board Statement: The study was conducted in accordance with the guidelines described in the Declaration of Helsinki and all procedures involving human subjects were approved by the Human Research Ethics Committee at the University of the Sunshine Coast (A/16/801, date of approval: 09/06/2016 and S/171/123, date of approval: 12 June 2017).

Informed Consent Statement: Informed consent was obtained from all subjects involved in the study.

Data Availability Statement: The data that support the findings of this study is available from the corresponding author upon reasonable request.

Acknowledgments: We thank our participants for their time and efforts that made this study possible. The authors are also grateful to Rebecca McClure and Michelle Barrett for their contribution toward data collection.

Conflicts of Interest: The authors declare that they have no competing interests.

\section{References}

1. McLeod, M.; Breen, L.; Hamilton, D.; Philp, A. Live strong and prosper: The importance of skeletal muscle strength for healthy ageing. Biogerontology 2016, 17, 497-510. [CrossRef]

2. Kalyani, R.R.; Corriere, M.; Ferrucci, L. Age-related and disease-related muscle loss: The effect of diabetes, obesity, and other diseases. Lancet Diabetes Endocrinol. 2014, 2, 819-829. [CrossRef]

3. McCormick, R.; Vasilaki, A. Age-related changes in skeletal muscle: Changes to life-style as a therapy. Biogerontology 2018, 19, 519-536. [CrossRef] [PubMed]

4. Violán, C.; Foguet-Boreu, Q.; Flores-Mateo, G.; Salisbury, C.; Blom, J.; Freitag, M.; Glynn, L.; Muth, C.; Valderas, J.M. Prevalence, Determinants and Patterns of Multimorbidity in Primary Care: A Systematic Review of Observational Studies. PLoS ONE 2014, 9, e102149. [CrossRef] 
5. Ng, M.; Fleming, T.; Robinson, M.; Thomson, B.; Graetz, N.; Margono, C.; Mullany, E.C.; Biryukov, S.; Abbafati, C.; Abera, S.F.; et al. Global, regional, and national prevalence of overweight and obesity in children and adults during 1980-2013: A systematic analysis for the Global Burden of Disease Study 2013. Lancet 2014, 384, 766-781. [CrossRef]

6. Gupta, P.; Lanca, C.; Gan, A.T.L.; Soh, P.; Thakur, S.; Tao, Y.; Kumari, N.; Man, R.E.K.; Fenwick, E.K.; Lamoureux, E.L. The Association between Body Composition using Dual energy X-ray Absorptiometry and Type-2 Diabetes: A Systematic Review and Meta-Analysis of Observational studies. Sci. Rep. 2019, 9, 1-10. [CrossRef]

7. Kalyani, R.R.; Metter, E.J.; Xue, Q.-L.; Egan, J.M.; Chia, C.W.; Studenski, S.; Shaffer, N.C.; Golden, S.; Al-Sofiani, M.; Florez, H.; et al. The Relationship of Lean Body Mass with Aging to the Development of Diabetes. J. Endocr. Soc. 2020, 4, bvaa043. [CrossRef] [PubMed]

8. Buscemi, C.; Ferro, Y.; Pujia, R.; Mazza, E.; Boragina, G.; Sciacqua, A.; Piro, S.; Pujia, A.; Sesti, G.; Buscemi, S.; et al. Sarcopenia and Appendicular Muscle Mass as Predictors of Impaired Fasting Glucose/Type 2 Diabetes in Elderly Women. Nutrients 2021, 13, 1909. [CrossRef]

9. Shou, J.; Chen, P.-J.; Xiao, W.-H. Mechanism of increased risk of insulin resistance in aging skeletal muscle. Diabetol. Metab. Syndr. 2020, 12, 1-10. [CrossRef]

10. Park, S.W.; Goodpaster, B.H.; Strotmeyer, E.; Kuller, L.H.; Broudeau, R.; Kammerer, C.M.; De Rekeneire, N.; Harris, T.B.; Schwartz, A.V.; Tylavsky, F.A.; et al. Accelerated Loss of Skeletal Muscle Strength in Older Adults with Type 2 Diabetes: The Health, Aging, and Body Composition Study. Diabetes Care 2007, 30, 1507-1512. [CrossRef] [PubMed]

11. Park, S.W.; Goodpaster, B.H.; Lee, J.S.; Kuller, L.H.; Boudreau, R.; De Rekeneire, N.; Harris, T.B.; Kritchevsky, S.; Tylavsky, F.A.; Nevitt, M.; et al. Excessive Loss of Skeletal Muscle Mass in Older Adults with Type 2 Diabetes. Diabetes Care 2009, 32, $1993-1997$. [CrossRef] [PubMed]

12. Leenders, M.; Verdijk, L.; van der Hoeven, L.; Adam, J.J.; van Kranenburg, J.; Nilwik, R.; van Loon, L.J. Patients with Type 2 Diabetes Show a Greater Decline in Muscle Mass, Muscle Strength, and Functional Capacity with Aging. J. Am. Med. Dir. Assoc. 2013, 14, 585-592. [CrossRef] [PubMed]

13. Mesinovic, J.; Zengin, A.; De Courten, B.; Ebeling, P.R.; Scott, D. Sarcopenia and type 2 diabetes mellitus: A bidirectional relationship. Diabetes Metab. Syndr. Obes. Targets Ther. 2019, 12, 1057-1072. [CrossRef]

14. Fritschi, C.; Bronas, U.G.; Park, C.G.; Collins, E.G.; Quinn, L. Early declines in physical function among aging adults with type 2 diabetes. J. Diabetes Complicat. 2017, 31, 347-352. [CrossRef]

15. Jing, X.; Chen, J.; Dong, Y.; Han, D.; Zhao, H.; Wang, X.; Gao, F.; Li, C.; Cui, Z.; Liu, Y.; et al. Related factors of quality of life of type 2 diabetes patients: A systematic review and meta-analysis. Health Qual. Life Outcomes 2018, 16, 189. [CrossRef]

16. Khan, M.A.B.; Hashim, M.J.; King, J.K.; Govender, R.D.; Mustafa, H.; Al Kaabi, J. Epidemiology of Type 2 Diabetes-Global Burden of Disease and Forecasted Trends. J. Epidemiol. Glob. Health 2020, 10, 107-111. [CrossRef]

17. Terranova, C.; Brakenridge, C.; Lawler, S.; Eakin, E.; Reeves, M.M. Effectiveness of lifestyle-based weight loss interventions for adults with type 2 diabetes: A systematic review and meta-analysis. Diabetes Obes. Metab. 2014, 17, 371-378. [CrossRef]

18. Lee, J.; Kim, D.; Kim, C. Resistance Training for Glycemic Control, Muscular Strength, and Lean Body Mass in Old Type 2 Diabetic Patients: A Meta-Analysis. Diabetes Ther. 2017, 8, 459-473. [CrossRef]

19. Locher, J.L.; Goldsby, T.U.; Goss, A.M.; Kilgore, M.L.; Gower, B.; Ard, J. Calorie restriction in overweight older adults: Do benefits exceed potential risks? Exp. Gerontol. 2016, 86, 4-13. [CrossRef]

20. Arnold, A.M.; Newman, A.B.; Cushman, M.; Ding, J.; Kritchevsky, S. Body Weight Dynamics and Their Association with Physical Function and Mortality in Older Adults: The Cardiovascular Health Study. J. Gerontol. Ser. A Boil. Sci. Med. Sci. 2010, 65, 63-70. [CrossRef] [PubMed]

21. Lee, J.S.; Visser, M.; Tylavsky, F.A.; Kritchevsky, S.; Schwartz, A.V.; Sahyoun, N.; Harris, T.B.; Newman, A.B.; the Health ABC Study. Weight Loss and Regain and Effects on Body Composition: The Health, Aging, and Body Composition Study. J. Gerontol. Ser. A Boil. Sci. Med. Sci. 2009, 65, 78-83. [CrossRef]

22. Kim, J.E.; O'Connor, L.E.; Sands, L.; Slebodnik, M.B.; Campbell, W.W. Effects of dietary protein intake on body composition changes after weight loss in older adults: A systematic review and meta-analysis. Nutr. Rev. 2016, 74, 210-224. [CrossRef] [PubMed]

23. Weinheimer, E.M.; Sands, L.; Campbell, W.W. A systematic review of the separate and combined effects of energy restriction and exercise on fat-free mass in middle-aged and older adults: Implications for sarcopenic obesity. Nutr. Rev. 2010, 68, 375-388. [CrossRef] [PubMed]

24. Miller, C.T.; Fraser, S.F.; Levinger, I.; Straznicky, N.E.; Dixon, J.B.; Reynolds, J.; Selig, S.E. The Effects of Exercise Training in Addition to Energy Restriction on Functional Capacities and Body Composition in Obese Adults during Weight Loss: A Systematic Review. PLoS ONE 2013, 8, e81692. [CrossRef] [PubMed]

25. Snorgaard, O.; Poulsen, G.M.; Andersen, H.K.; Astrup, A. Systematic review and meta-analysis of dietary carbohydrate restriction in patients with type 2 diabetes. BMJ Open Diabetes Res. Care 2017, 5, e000354. [CrossRef]

26. Hu, F.B. Dietary pattern analysis: A new direction in nutritional epidemiology. Curr. Opin. Lipidol. 2002, 13, 3-9. [CrossRef] [PubMed]

27. Esposito, K.; Maiorino, M.I.; Bellastella, G.; Chiodini, P.; Panagiotakos, D.B.; Giugliano, D. A journey into a Mediterranean diet and type 2 diabetes: A systematic review with meta-analyses. BMJ Open 2015, 5, e008222. [CrossRef] 
28. Pan, B.; Wu, Y.; Yang, Q.; Ge, L.; Gao, C.; Xun, Y.; Tian, J.; Ding, G. The impact of major dietary patterns on glycemic control, cardiovascular risk factors, and weight loss in patients with type 2 diabetes: A network meta-analysis. J. Evid.-Based Med. 2018, 12, 29-39. [CrossRef]

29. Donini, L.; Serra-Majem, L.; Bulló, M.; Gil, A.; Salas-Salvadó, J. The Mediterranean diet: Culture, health and science. Br. J. Nutr. 2015, 113, S1-S3. [CrossRef]

30. Bach-Faig, A.; Berry, E.M.; Lairon, D.; Reguant, J.; Trichopoulou, A.; Dernini, S.; Medina, F.X.; Battino, M.; Belahsen, R.; Miranda, G.; et al. Mediterranean diet pyramid today. Science and cultural updates. Public Health Nutr. 2011, 14, 2274-2284. [CrossRef]

31. Trichopoulou, A. Diversity v. globalization: Traditional foods at the epicentre. Public Health Nutr. 2012, 15, 951-954. [CrossRef] [PubMed]

32. Willett, W.C.; Sacks, F.; Trichopoulou, A.; Drescher, G.; Ferro-Luzzi, A.; Helsing, E.; Trichopoulos, D. Mediterranean diet pyramid: A cultural model for healthy eating. Am. J. Clin. Nutr. 1995, 61, 1402S-1406S. [CrossRef] [PubMed]

33. Villani, A.; Sultana, J.; Doecke, J.; Mantzioris, E. Differences in the interpretation of a modernized Mediterranean diet prescribed in intervention studies for the management of type 2 diabetes: How closely does this align with a traditional Mediterranean diet? Eur. J. Nutr. 2018, 58, 1369-1380. [CrossRef] [PubMed]

34. McClure, R.; Villani, A. Mediterranean Diet attenuates risk of frailty and sarcopenia: New insights and future directions. JCSM Clin. Rep. 2017, 2, 1-17. [CrossRef]

35. Wang, Y.; Hao, Q.; Su, L.; Liu, Y.; Liu, S.; Dong, B. Adherence to the Mediterranean Diet and the Risk of Frailty in Old People: A Systematic Review and Meta-Analysis. J. Nutr. Health Aging 2018, 22, 613-618. [CrossRef]

36. Silva, R.; Pizato, N.; Da Mata, F.; Figueiredo, A.; Ito, M.; Pereira, M.G. Mediterranean Diet and Musculoskeletal-Functional Outcomes in Community-Dwelling Older People: A Systematic Review and Meta-Analysis. J. Nutr. Health Aging 2018, 22, 655-663. [CrossRef]

37. Tepper, S.; Sivashensky, A.A.; Shahar, D.R.; Geva, D.; Cukierman-Yaffe, T. The Association between Mediterranean Diet and the Risk of Falls and Physical Function Indices in Older Type 2 Diabetic People Varies by Age. Nutrients 2018, 10, 767. [CrossRef]

38. McClure, R.; Villani, A. Greater adherence to a Mediterranean Diet is associated with better gait speed in older adults with type 2 diabetes mellitus. Clin. Nutr. ESPEN 2019, 32, 33-39. [CrossRef]

39. Papadaki, A.; Nolen-Doerr, E.; Mantzoros, C.S. The Effect of the Mediterranean Diet on Metabolic Health: A Systematic Review and Meta-Analysis of Controlled Trials in Adults. Nutrients 2020, 12, 3342. [CrossRef]

40. Boghossian, N.S.; the BioCycle Study Group; Yeung, E.H.; Mumford, S.L.; Zhang, C.; Gaskins, A.J.; Wactawski-Wende, J.; Schisterman, E. Adherence to the Mediterranean diet and body fat distribution in reproductive aged women. Eur. J. Clin. Nutr. 2013, 67, 289-294. [CrossRef]

41. Villani, A.; Wright, H.; Slater, G.; Buckley, J. A randomised controlled intervention study investigating the efficacy of carotenoidrich fruits and vegetables and extra-virgin olive oil on attenuating sarcopenic symptomology in overweight and obese older adults during energy intake restriction: Protocol paper. BMC Geriatr. 2018, 18, 2. [CrossRef]

42. Villani, A.; McClure, R.; Barrett, M.; Scott, D. Diagnostic differences and agreement between the original and revised European Working Group (EWGSOP) consensus definition for sarcopenia in community-dwelling older adults with type 2 diabetes mellitus. Arch. Gerontol. Geriatr. 2020, 89, 104081. [CrossRef]

43. Baumgartner, R.N.; Koehler, K.M.; Gallagher, D.; Romero, L.; Heymsfield, S.B.; Ross, R.R.; Garry, P.J.; Lindeman, R.D. Epidemiology of Sarcopenia among the Elderly in New Mexico. Am. J. Epidemiol. 1998, 147, 755-763. [CrossRef]

44. Nana, A.; Slater, G.; Hopkins, W.G.; Burke, L.M. Effects of Daily Activities on Dual-Energy X-ray Absorptiometry Measurements of Body Composition in Active People. Med. Sci. Sports Exerc. 2012, 44, 180-189. [CrossRef] [PubMed]

45. Guralnik, J.M.; Simonsick, E.M.; Ferrucci, L.; Glynn, R.J.; Berkman, L.F.; Blazer, D.G.; Scherr, P.A.; Wallace, R.B. A Short Physical Performance Battery Assessing Lower Extremity Function: Association with Self-Reported Disability and Prediction of Mortality and Nursing Home Admission. J. Gerontol. 1994, 49, M85-M94. [CrossRef] [PubMed]

46. Martínez-González, M.A.; García-Arellano, A.; Toledo, E.; Salas-Salvadó, J.; Buil-Cosiales, P.; Corella, D.; Covas, M.I.; Schröder, H.; Arós, F.; Gómez-Gracia, E.; et al. A 14-Item Mediterranean Diet Assessment Tool and Obesity Indexes among High-Risk Subjects: The PREDIMED Trial. PLoS ONE 2012, 7, e43134. [CrossRef]

47. Rezagholizadeh, F.; Djafarian, K.; Khosravi, S.; Shab-Bidar, S. A posteriori healthy dietary patterns may decrease the risk of central obesity: Findings from a systematic review and meta-analysis. Nutr. Res. 2017, 41, 1-13. [CrossRef]

48. Bendall, C.L.; Mayr, H.; Opie, R.; Bes-Rastrollo, M.; Itsiopoulos, C.; Thomas, C.J. Central obesity and the Mediterranean diet: A systematic review of intervention trials. Crit. Rev. Food Sci. Nutr. 2018, 58, 3070-3084. [CrossRef]

49. Ajala, O.; English, P.; Pinkney, J. Systematic review and meta-analysis of different dietary approaches to the management of type 2 diabetes. Am. J. Clin. Nutr. 2013, 97, 505-516. [CrossRef]

50. Huo, R.; Du, T.; Xu, Y.; Xu, W.; Chen, X.; Sun, K.; Yu, X. Effects of Mediterranean-style diet on glycemic control, weight loss and cardiovascular risk factors among type 2 diabetes individuals: A meta-analysis. Eur. J. Clin. Nutr. 2015, 69, 1200-1208. [CrossRef]

51. Vitale, M.; Masulli, M.; Calabrese, I.; Rivellese, A.A.; Bonora, E.; Signorini, S.; Perriello, G.; Squatrito, S.; Buzzetti, R.; Sartore, G.; et al. Impact of a Mediterranean Dietary Pattern and Its Components on Cardiovascular Risk Factors, Glucose Control, and Body Weight in People with Type 2 Diabetes: A Real-Life Study. Nutrients 2018, 10, 1067. [CrossRef] 
52. Lasa, A.; Miranda, J.; Bulló, M.; Casas, R.; Salas-Salvadó, J.; Larretxi, I.; Estruch, R.; Ruiz-Gutiérrez, V.; Portillo, M.P. Comparative effect of two Mediterranean diets versus a low-fat diet on glycaemic control in individuals with type 2 diabetes. Eur. J. Clin. Nutr. 2014, 68, 767-772. [CrossRef]

53. Granic, A.; Sayer, A.A.; Robinson, S.M. Dietary Patterns, Skeletal Muscle Health, and Sarcopenia in Older Adults. Nutrients 2019, 11, 745. [CrossRef] [PubMed]

54. Lombardo, M.; Perrone, M.A.; Guseva, E.; Aulisa, G.; Padua, E.; Bellia, C.; Della-Morte, D.; Iellamo, F.; Caprio, M.; Bellia, A. Losing Weight after Menopause with Minimal Aerobic Training and Mediterranean Diet. Nutrients 2020, 12, 2471. [CrossRef] [PubMed]

55. Davis, C.R.; Bryan, J.; Hodgson, J.M.; Murphy, K.J. Definition of the Mediterranean Diet; A Literature Review. Nutrients 2015, 7, 9139-9153. [CrossRef]

56. Schröder, H. Protective mechanisms of the Mediterranean diet in obesity and type 2 diabetes. J. Nutr. Biochem. 2007, 18, 149-160. [CrossRef] [PubMed]

57. Salas-Salvadó, J.; Guasch-Ferré, M.; Lee, C.-H.; Estruch, R.; Clish, C.; Ros, E. Protective Effects of the Mediterranean Diet on Type 2 Diabetes and Metabolic Syndrome. J. Nutr. 2015, 146, 920S-927S. [CrossRef]

58. Rodríguez-Rejón, A.I.; Castro-Quezada, I.; Ruano-Rodríguez, C.; Ruiz-López, M.D.; Villegas, A.S.; Toledo, E.; Artacho, R.; Estruch, R.; Salas-Salvadó, J.; Covas, M.I.; et al. Effect of a Mediterranean Diet Intervention on Dietary Glycemic Load and Dietary Glycemic Index: The PREDIMED Study. J. Nutr. Metab. 2014, 2014, 1-10. [CrossRef]

59. Piers, L.S.; Walker, K.Z.; Stoney, R.M.; Soares, M.J.; O'Dea, K. Substitution of saturated with monounsaturated fat in a 4-week diet affects body weight and composition of overweight and obese men. Br. J. Nutr. 2003, 90, 717-727. [CrossRef]

60. Soares, M.J.; Cummings, S.J.; Mamo, J.C.L.; Kenrick, M.; Piers, L.S. The acute effects of olive oil v. cream on postprandial thermogenesis and substrate oxidation in postmenopausal women. Br. J. Nutr. 2004, 91, 245-252. [CrossRef]

61. Shahar, D.R.; Houston, D.; Hue, T.F.; Lee, J.-S.; Sahyoun, N.; Tylavsky, F.A.; Geva, D.; Vardi, H.; Harris, T.B. Adherence to Mediterranean Diet and Decline in Walking Speed over 8 Years in Community-Dwelling Older Adults. J. Am. Geriatr. Soc. 2012, 60, 1881-1888. [CrossRef] [PubMed]

62. León-Muñoz, L.M.; Guallar-Castillón, P.; López-García, E.; Rodríguez-Artalejo, F. Mediterranean Diet and Risk of Frailty in Community-Dwelling Older Adults. J. Am. Med. Dir. Assoc. 2014, 15, 899-903. [CrossRef]

63. Talegawkar, S.A.; Bandinelli, S.; Bandeen-Roche, K.; Chen, P.; Milaneschi, Y.; Tanaka, T.; Semba, R.D.; Guralnik, J.M.; Ferrucci, L. A Higher Adherence to a Mediterranean-Style Diet Is Inversely Associated with the Development of Frailty in Community-Dwelling Elderly Men and Women. J. Nutr. 2012, 142, 2161-2166. [CrossRef] [PubMed]

64. Barrea, L.; Muscogiuri, G.; Di Somma, C.; Tramontano, G.; De Luca, V.; Illario, M.; Colao, A.; Savastano, S. Association between Mediterranean diet and hand grip strength in older adult women. Clin. Nutr. 2019, 38, 721-729. [CrossRef]

65. Kim, H.; Kwon, O. Higher Diet Quality is Associated with Lower Odds of Low Hand Grip Strength in the Korean Elderly Population. Nutrients 2019, 11, 1487. [CrossRef]

66. Mendes, J.; Afonso, C.; Borges, N.; Santos, A.; Moreira, P.; Padrão, P.; Negrão, R.; Amaral, T.F. Adherence to a Mediterranean Dietary Pattern and Functional Parameters: A Cross-Sectional Study in an Older Population. J. Nutr. Health Aging 2019, 24, 138-146. [CrossRef] [PubMed]

67. Fougère, B.; Mazzuco, S.; Spagnolo, P.; Guyonnet, S.; Vellas, B.; Cesari, M.; Gallucci, M. Association between the Mediterraneanstyle dietary pattern score and physical performance: Results from TRELONG study. J. Nutr. Health Aging 2016, 20, 415-419. [CrossRef]

68. Isanejad, M.; Sirola, J.; Mursu, J.; Rikkonen, T.; Kröger, H.; Tuppurainen, M.; Erkkilä, A.T. Association of the Baltic Sea and Mediterranean diets with indices of sarcopenia in elderly women, OSPTRE-FPS study. Eur. J. Nutr. 2017, 57, 1435-1448. [CrossRef]

69. Martínez-González, M.A.; Hershey, M.S.; Zazpe, I.; Trichopoulou, A. Transferability of the Mediterranean Diet to NonMediterranean Countries. What Is and What Is Not the Mediterranean Diet. Nutrients 2017, 9, 1226. [CrossRef]

70. Hutchins-Wiese, H.L.; Bales, C.W.; Starr, K.N.P. Mediterranean diet scoring systems: Understanding the evolution and applications for Mediterranean and non-Mediterranean countries. Br. J. Nutr. 2021, 1-22. [CrossRef]

71. Billingsley, H.E.; Carbone, S. The antioxidant potential of the Mediterranean diet in patients at high cardiovascular risk: An in-depth review of the PREDIMED. Nutr. Diabetes 2018, 8, 13. [CrossRef] [PubMed]

72. Chung, H.Y.; Cesari, M.; Anton, S.; Marzetti, E.; Giovannini, S.; Seo, A.Y.; Carter, C.; Yu, B.P.; Leeuwenburgh, C. Molecular inflammation: Underpinnings of aging and age-related diseases. Ageing Res. Rev. 2009, 8, 18-30. [CrossRef] [PubMed]

73. Schaap, L.A.; Pluijm, S.M.; Deeg, D.J.; Visser, M. Inflammatory Markers and Loss of Muscle Mass (Sarcopenia) and Strength. Am. J. Med. 2006, 119, 526.e9-526.e17. [CrossRef] [PubMed]

74. Grosicki, G.J.; Barrett, B.B.; Englund, D.A.; Liu, C.; Travison, T.G.; Cederholm, T.; Koochek, A.; von Berens, Å.; Gustafsson, T.; Benard, T.; et al. Circulating Interleukin-6 is Associated with Skeletal Muscle Strength, Quality, and Functional Adaptation with Exercise Training in Mobility-Limited Older Adults. J. Frailty Aging 2019, 9, 1-7. [CrossRef]

75. Calvani, R.; Marini, F.; Cesari, M.; Buford, T.W.; Manini, T.M.; Pahor, M.; Leeuwenburgh, C.; Bernabei, R.; Landi, F.; Marzetti, E. Systemic inflammation, body composition, and physical performance in old community-dwellers. J. Cachex-Sarcopenia Muscle 2016, 8, 69-77. [CrossRef] 
76. Tangvarasittichai, S.; Pongthaisong, S.; Tangvarasittichai, O. Tumor Necrosis Factor-A, Interleukin-6, C-Reactive Protein Levels and Insulin Resistance Associated with Type 2 Diabetes in Abdominal Obesity Women. Indian J. Clin. Biochem. 2016, 31, 68-74. [CrossRef]

77. Nani, A.; Murtaza, B.; Khan, A.S.; Khan, N.; Hichami, A. Antioxidant and Anti-Inflammatory Potential of Polyphenols Contained in Mediterranean Diet in Obesity: Molecular Mechanisms. Molecules 2021, 26, 985. [CrossRef]

78. Sugimoto, K.; Ikegami, H.; Takata, Y.; Katsuya, T.; Fukuda, M.; Akasaka, H.; Tabara, Y.; Osawa, H.; Hiromine, Y.; Rakugi, H. Glycemic Control and Insulin Improve Muscle Mass and Gait Speed in Type 2 Diabetes: The MUSCLES-DM Study. J. Am. Med. Dir. Assoc. 2021, 22, 834-838.e1. [CrossRef]

79. Uchida, S.; Kamiya, K.; Hamazaki, N.; Matsuzawa, R.; Nozaki, K.; Ichikawa, T.; Suzuki, Y.; Nakamura, T.; Yamashita, M.; Kariya, H.; et al. Association between sarcopenia and atherosclerosis in elderly patients with ischemic heart disease. Heart Vessel. 2020, 35, 769-775. [CrossRef] [PubMed]

80. Tuttle, C.S.; Thang, L.A.; Maier, A.B. Markers of inflammation and their association with muscle strength and mass: A systematic review and meta-analysis. Ageing Res. Rev. 2020, 64, 101185. [CrossRef]

81. Hsu, K.-J.; Liao, C.-D.; Tsai, M.-W.; Chen, C.-N. Effects of Exercise and Nutritional Intervention on Body Composition, Metabolic Health, and Physical Performance in Adults with Sarcopenic Obesity: A Meta-Analysis. Nutrients 2019, 11, 2163. [CrossRef] [PubMed]

82. Ishiguro, H.; Kodama, S.; Horikawa, C.; Fujihara, K.; Hirose, A.S.; Hirasawa, R.; Yachi, Y.; Ohara, N.; Shimano, H.; Hanyu, O.; et al. In Search of the Ideal Resistance Training Program to Improve Glycemic Control and its Indication for Patients with Type 2 Diabetes Mellitus: A Systematic Review and Meta-Analysis. Sports Med. 2015, 46, 67-77. [CrossRef] [PubMed]

83. Apolzan, J.W.; Venditti, E.M.; Edelstein, S.L.; Knowler, W.C.; Dabelea, D.; Boyko, E.J.; Pi-Sunyer, X.; Kalyani, R.R.; Franks, P.W.; Srikanthan, P.; et al. Long-Term Weight Loss with Metformin or Lifestyle Intervention in the Diabetes Prevention Program Outcomes Study. Ann. Intern. Med. 2019, 170, 682-690. [CrossRef] [PubMed] 